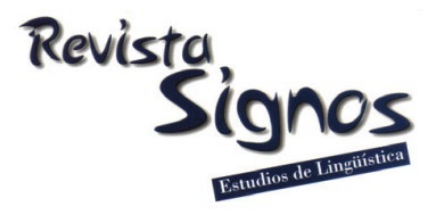

\title{
'Su' aproximativo, ponderativo y afectivo en el habla de Santiago de Chile: Estudio gramatical y sociolingüístico ${ }^{1}$
}

\author{
Approximative, ponderative and affective 'su' of speakers in \\ Santiago, Chile: A grammatical and sociolinguistic study
}

Silvana Arriagada

Anabalón²

UNIVERSIDAD DE CHILE

CHILE

sbarriagada@uc.cl

\author{
Silvana Guerrero González \\ UNIVERSIDAD DE CHILE \\ CHILE \\ siguerrero@u.uchile.cl
}

Raïssa Kordic
Riquelme
UNIVERSIDAD DE CHLE
CHILE
raissa.kordic@gmail.com

Recibido: 21-IX-2017 / Aceptado: 29-X-2018

DOI: $10.4067 /$ S0718-09342019000300830

\section{Resumen}

En esta investigación se presenta una caracterización del uso coloquial de 'su' en el habla de Santiago de Chile, en dos dimensiones: gramatical y sociolingüística. Primero, se realiza una revisión histórica, la que nos permite señalar que el empleo coloquial de 'su', aproximativo, ponderativo y afectivo, con función más bien de determinante, tiene sus orígenes en la lengua latina y lo encontramos testimoniado tempranamente en España y posteriormente en otros países hispanoamericanos. Luego de la revisión de 108 entrevistas sociolingüísticas, podemos concluir que el 'su' como determinante afectivo constituye un valor del posesivo diferenciado, no descrito en las gramáticas ni en estudios posteriores. Junto con esto, concluimos que es posible agrupar los casos en los que se usa 'su' en cinco ejes temáticos: 1) bebidas y licores, 2) alimentos, 3) utensilios domésticos o posesiones importantes, 4) actividades, procesos y eventos y 5) seres humanos. Finalmente, los hallazgos sobre la distribución sociolingüística del fenómeno nos permiten comprobar la hipótesis inicial, ya que se trata de un fenómeno que se halla más en los hablantes hombres de la comunidad de habla en estudio, en especial, en los jóvenes con menos nivel de estudios.

Palabras Clave: 'Su' afectivo, uso coloquial, lingüística histórica, caracterización gramatical, variación sociolingüística. 


\begin{abstract}
This investigation presents a characterization of the colloquial usage of the word su' of Santiago de Chile speakers within two dimensions: grammatical and sociolinguistic. First, a historical review allows to indicate that the colloquial use of approximative, ponderative and affective 'su', with a mostly determining function, has its origins in Latin language and can be found in early Spanish testimonies and subsequently in other Hispano-American countries. After the revision of 108 sociolinguistic interviews, it can be concluded that the use of 'su' as an affective determinant constitutes a possessive differentiated value, not described neither in grammars nor in any following studies. Along with this, it is concluded that it is possible to group these usage cases of 'su' in five thematic axes: 1) refreshments and liquors, 2) food, 3) home utensils or important possessions, 4) events, processes and activities and 5) human beings. Finally, findings about the sociolinguistic distribution in the phenomenon allows the corroboration of the initial hypothesis, since this is a phenomenon that is found more in male speakers of the studied parole community, especially in young men with lower study levels.
\end{abstract}

Key Words: Affective 'su', colloquial use, historical linguistics, grammatical characterization, sociolinguistic variation.

\title{
INTRODUCCIÓN
}

El determinante 'su' en el español de Santiago de Chile no solo refiere a una relación de posesión entre una persona gramatical, a la que llamaremos [x], de segunda (usted) o tercera persona (él, ella, ellos, ellas), y un elemento [y] , como lo muestra el caso (1), sino que además, en muchas ocasiones, evidencia un uso afectivo en ciertos contextos en los que, a diferencia de su uso tradicional, no es tan clara la relación con una persona gramatical particular, como queda de manifiesto en el caso (2):

(1) mi profesora era una profesora de nacionalidad uruguaya / entonces tenía ella su modalidad del lenguaje (SCHI_H31_025) ${ }^{3}($ ella $=[\mathrm{x}]$; modalidad del lenguaje $=[\mathrm{y}]$; su $[\mathrm{y}]=\mathrm{la}[\mathrm{y}]$ de $[\mathrm{x}])$.

(2) ¿qué se toma ahí? vino // vino/ su ponchecillo // vino durazno no sé (SCHI_H13_074).

Mientras que en el caso (1) la forma correspondiente podría reemplazarse por una estructura gramatical equivalente, como lo es el complemento del nombre con valor genitivo 'de ella', en el caso (2) no se justificaría tan claramente una relación entre ponchecillo y el pronombre yo, único referente explícito al que podría vincularse, haciendo por tanto imposible e injustificado el reemplazo. En cuanto a [x], debe entenderse por posesión no necesariamente un sentido de pertenencia material, sino también, como señala Alarcos (1999), como una vinculación o relación preferente entre un elemento o entidad particular y una de las personas gramaticales de la lengua española. En [y] el determinante posesivo también se asocia al pronombre indefinido uno (su $\rightarrow$ de uno). Según el DPD (RAE, 2015): 
"el pronombre indefinido uno puede usarse con referencia al yo que habla. Lo normal en ese caso es establecer la concordancia de género en función del sexo de la persona que habla: «Una ya no está para esos trotes» (RGodoy Mujer [Esp. 1990]). Pero si la mujer que habla no hace alusión directa a sí misma, sino que habla en términos generales, podrá usar el indefinido uno, aludiendo al ser humano en general".

En estos casos, no obstante, es posible reemplazar el determinante 'su' por un artículo, sin embargo, de hacerlo, el enunciado perdería, en parte, su valor afectivo y ponderativo. A este respecto, precisamos que a diferencia de lo que sucede con el uso tradicional del determinante posesivo, el uso afectivo permite el reemplazo por un artículo indefinido. Así, en el caso del ejemplo expuesto, es admisible la conmutación por la forma: tomo un ponchecillo. Lo anterior es un aspecto diferenciador fundamental de ambos usos, pues, como señala Costa (1981), un sintagma nominal como mi libro equivale a el libro mío, pero no a un libro mío.

Considerando la relevancia que adquiere la forma coloquial de 'su' en Chile, esto es, aproximativo, ponderativo y afectivo, en esta investigación se realiza una caracterización del fenómeno en dos dimensiones: se presentan su descripción gramatical y su distribución sociolingüística con base en los materiales del Corpus del Proyecto para el Estudio Sociolingüístico del Español de España y América (PRESEEA) correspondiente al habla de Santiago de Chile. Respecto de la descripción gramatical, se estudia su comportamiento sintáctico y se propone una primera clasificación y categorización semántico-discursiva de sus usos; se trata, en esta etapa del estudio, de una propuesta general. En lo referido a la distribución sociolingüística, se estudia la asociación de 'su' con las variables sexo, edad y nivel de estudios de los informantes. En este caso, se maneja la hipótesis de que las características sociodemográficas de los hablantes de español en Santiago de Chile están asociadas con el empleo del fenómeno en estudio, y que sería más frecuente en los hablantes hombres de la comunidad de habla en estudio.

Se destaca como relevancia de la investigación no solo su aporte teórico en lo que refiere a los llamados posesivos españoles, sino además su contribución a la descripción histórica, gramatical y sociolingüística de un fenómeno actual característico del español hablado en Santiago de Chile. Además de lo anterior, este trabajo se propone construir, en términos descriptivos, una primera clasificación y categorización semántico-discursiva de los contextos de aparición del fenómeno, lo que provee una visión integrada e interdisciplinar de un valor no descrito ni abordado en estudios anteriores. 


\section{Marco teórico}

\subsection{Los posesivos en español}

Según la RAE (2010: 115), bajo la categoría semántica de posesivos se encuentran diversas categorías gramaticales, tales como modificadores (adjetivos), pronombres y determinantes, que "expresan posesión o pertenencia, como 'mi', 'tu', 'su', 'mío', 'tuyo', 'suyo"'. Estas expresiones equivalen, frecuentemente, a grupos preposicionales encabezados por la preposición 'de', que, en uno de sus valores, vincula a un referente (poseído o pertenecido) con su poseedor (De Bruyne, 1999). Además de lo anterior y como característica distintiva, al igual que los pronombres personales, los posesivos presentan y evidencian el rasgo de persona gramatical.

En lo que refiere a los valores del determinante posesivo 'su' (posición prenominal), siguiendo a Morera (1987), si se concibe esta forma en el marco del paradigma de la segunda persona singular, se trata de una forma de respeto asociada al pronombre honorífico usted ('su' $\rightarrow$ de usted) y, por tanto, a un reflejo del distanciamiento producto de una relación jerárquica entre los interlocutores. Lo anterior resulta relevante como antecedente, pues una posible lectura de la interpretación afectiva del determinante 'su', si se concibe asociado a la segunda persona, podría ser el uso de una forma de respeto en un contexto no requerido con un sentido más bien lúdico, que tendría por objetivo la resignificación del sentido honorífico asociado al determinante correspondiente. Ahora bien, si su interpretación se asociase a la tercera persona, podría entenderse como un distanciamiento intencionado, cuyo efecto de sentido sería parafraseable por y es propio de $z$, donde y es el lexema nuclear correspondiente y $\mathrm{z}$ es una circunstancia espacio temporal o un contexto en el que la forma $y$ es característica, como lo muestra el siguiente ejemplo, en el que se le pregunta al informante qué actividades o comidas realiza para navidad:

(3) se hace su comidita / su papitas con mayo / su arrocito / yo creo que en / que en casi todos los lados es igual (SCHI_H12_037).

Entendemos por distanciamiento o alejamiento, en este contexto, una intención de levantar una especie de principio sobre algo que no dependa del hablante ni del oyente (compartiendo, por tanto, ciertos rasgos semánticos con la llamada 'impersonalización'). En este sentido, la relación establecida por el posesivo se da entre el elemento y un elemento externo, no interno al intercambio comunicativo. Esta idea podría sustentarse en la atribución de no persona que se le da a la tercera persona gramatical. Benveniste (1970) dirá que mientras los pronombres de primera y segunda refieren a participantes del proceso de enunciación, los de tercera no, pues se relacionan más bien con un espacio externo al proceso de la enunciación, cambiando, por tanto, 'su matriz de rasgos semánticos' (Morera, 1987). Se afirma que se trata de 
una tercera persona ficticia que surge ante la necesidad de atribuir un elemento a un tercero imaginario (Morera, 1987).

En lo que refiere a valores que trasciendan la vinculación de posesión ya descrita, diversos autores han reconocido ciertos sentidos que podrían interpretarse como afectivos, mas no aplicables al uso presente en el español de Santiago de Chile (Morera, 1987; García, 1990), pues refieren más bien a relaciones necesariamente atributivas $^{4}$ (el 'su' funciona como un reforzador o enfatizador de la relación atributiva existente entre dos referentes) o a usos del determinante ante nombre propio, uso íntimo, de naturaleza familiar (García, 1990). Sobre esto, se precisa que la posibilidad de aparecer asociado a nombres propios es más bien restringida en el caso del determinante 'su' afectivo y enfático que estudiamos, debido a que su valor se asocia a un polo de menor definitud (de ahí la posibilidad de vincularlo al artículo indefinido, como se expuso anteriormente). Sin embargo, también se registran casos que responden a esta estructura, mas adquieren un valor distinto, pues no se trata de nombres propios asociados a entidades animadas.

\subsubsection{Caracterización de la partícula 'su' en español}

Postular un nuevo uso del determinante posesivo supone, entonces, una diferenciación semántica y pragmática del uso tradicional. En la bibliografía consultada no se proveen estrategias específicas de identificación y diferenciación, por lo tanto, el enfoque y la dimensión del fenómeno analizado son inéditos. Tomamos, sin embargo, las características que se proporcionan para los posesivos en su uso tradicional, con el propósito de detallar las estrategias analíticas que guiarán la identificación y el análisis de las formas correspondientes. Estas responden a una reelaboración por oposición y diferenciación de las características tradicionales (Tesnière, 1994; Alarcos, 1999; Torrego, 1997; Bosque \& Demonte, 1999; Varela, 2005; Di Tullio, 2007). Asimismo, se trabaja sobre la base de una propuesta personal para su identificación.

a) Imposibilidad de alternar de posición ante la variación de sentido. El uso afectivo del 'su' no permite la alternación a una posición postnominal, pues se pierde su valor afectivo valorativo. Así, es posible el cambio de posición en $\mathrm{mi} / \mathrm{tu} / \mathrm{su}$ libro $\rightarrow$ el libro mío/tuyo/suyo (con el correspondiente cambio a un determinante artículo para evitar la redundancia), mas no en la cena tiene sus buenas papas con mayo y su ensaladita ya a la chilena, que, ante la alternación altera su valor original y pierde, parcialmente, su evaluación positiva y cercana con el referente correspondiente $\rightarrow *$ la cena tiene las buenas papas con mayo suyas y la ensaladita suya ya a la chilena ${ }^{5}$.

b) Ausencia de un antecedente expreso. A diferencia de los posesivos de primera o segunda persona, el determinante 'su' puede tener una interpretación ambigua, por lo que se hace necesaria la manifestación expresa de un antecedente inmediato (por su alternancia de uso en la segunda y tercera 
persona). En el uso tradicional esto se cumple en la mayoría de los casos. No obstante, en el uso afectivo hasta aquí tratado, no existe un elemento asociado expreso; en ocasiones puede tornarse indeterminado, mientras que en otras inexistentes, como lo muestra el caso (4). A este respecto, existe una pregunta instrumental que hace patente esta ausencia: ¿a qué o quién se vincula los lexemas atraque, cervecita o vino? La dificultad que supone el reconocimiento y postulación de un elemento del enunciado pone aún más de manifiesto esta característica:

(4) de todo [hacíamos] pues compadre / de todo / de todo // su atraque y de todo / si estábamos solos en la casa de ella // y comprábamos su cervecita / su vinito / lo que quisiéramos tomar (SCHI_H12_037).

Esta segunda característica no debe separarse de la primera: la inexistencia de un antecedente o elemento asociado se relaciona directamente con la ausencia de un referente pronominal específico. Sobre esto, el 'su' afectivo se vincula además con el pronombre indefinido uno, lo que refuerza las características de indeterminación antes mencionadas, como lo muestran los ejemplos (5) y (6).

(5) que es lo infaltable / en una cena así / y su buen trozo de pan de pascua /ponche / cola de mono / que es lo típico que uno come pues (SCHI_H22_052).

(6) no me gusta el modo de cómo / cómo se visten / antes era uno por ejemplo usaba su cotonita (SCHI_H21_014).

c) El posesivo con valor afectivo puede aparecer con el verbo haber. Según Eguren (2013: 209), los posesivos prenominales, al igual que los artículos determinados, son determinantes definidos, pues, en palabras del autor "ambas formas identifican entidades previamente mencionadas o conocidas. Prueba de ello es que no pueden aparecer en contextos presentacionales como los creados por el verbo haber". Si bien esto se cumple con el uso tradicional (así, por ejemplo, una expresión como *había su perro en la fiesta es agramatical), el uso afectivo admite construcciones con haber existencial. Según esto, una expresión como había sus buenas minitas en la fiesta es gramatical y aceptable en tanto tiene un sentido particular.

d) La estructura en la que se encuentra el 'su' afectivo desempeña, preponderantemente, la función de objeto directo. En lo que refiere a aspectos sintácticos, los determinantes posesivos pueden formar parte de estructuras que desempeñen diversas funciones sintácticas. Un determinante 'su' con valor afectivo, no obstante, se presenta en sintagmas que desempeñan la función de objeto directo, preponderantemente. De presentarse en sintagmas que cumplen la función de sujeto, la interpretación se vuelve ambigua (pudiendo incluso 
interpretarse como un posesivo tradicional). Así, por ejemplo, en un uso como el de (7),

(7) hacemos su cocimiento / yo empresto la casa (SCHI_H12_039).

Si se cambiase la proposición a una en la que su cocimiento fuera el sujeto, la interpretación afectiva no se hace tan patente. Incluso, podría tornarse ambigua: su cocimiento es bueno para la salud (un enunciado como este, potencialmente, podría llevar a la pregunta ¿de quién o qué?).

\subsubsection{Antecedentes históricos de la partícula 'su' en español}

Los antecedentes históricos del uso de 'su' que acá nos ocupa se remontan a varios siglos y a un ámbito general de uso de la lengua española, incluso latina, si bien existen matices locales que explicitaremos.

Jiménez (2006: 153), analizando la "gramaticalización de los posesivos y su conversión en determinantes"،, cuyo origen sitúa en la época latina, con distinta evolución según las lenguas, cita a Company (1991: 62) para referir al cambio de valor y función del posesivo en su uso como determinante:

"los datos del corpus sugieren que diacrónicamente el pronombre posesivo alteró en su evolución sintáctica el equilibrio entre sus dos funciones esenciales: debilitó su función relacional anafórica y fortaleció su función presentativa, con lo cual se aproximó al artículo, entró en distribución complementaria con él y terminó por incluirse en la clase de los determinantes".

Añade Jiménez (2006), citando a Company (1991), que este cambio de naturaleza del posesivo tiene su origen en la forma de tercera persona 'su(s)' y su falta de transparencia para referir al poseedor. Esta ambigüedad en cuanto a la persona, acentuada en el español de América, y también en cuanto al género, aceleró, primero, la liberación de su referencia al sujeto, ya que no hay que olvidar que la forma suns-aum era inicialmente el posesivo reflexivo, frente a eius-a-um y, posteriormente, la necesidad de anclaje referencial.

El DRAE (RAE, 2005) le atribuye a 'su', en una tercera acepción, un valor 'coloquial', 'enfático y afectivo', y ya no propiamente posesivo, como los de las primeras acepciones, ejemplificando con: 'siempre está hablando de su Luis'. En este caso, es posible apreciar que el posesivo correspondiente marca una relación cercana o vinculación preferente entre dos sujetos, como menciona Alarcos (1999). Sobre el valor aproximativo y/o ponderativo, este es omitido, a pesar de ser destacado en diccionarios de chilenismos y otras fuentes generales. Encontramos, por ejemplo, en el Corpus Diacrónico del Español (CORDE) de la RAE, antecedentes en España (s. XVII), especialmente en la literatura de tipo popular o costumbrista, donde todavía se conserva: 
(a) "Lo otro que pides no se usa en esta tierra ni pertenece a mi reino. Baile del sacristán; dice a la gala. También el sacristán bailó su poquito y aun zapateó un si es no es, y aun algo más de lo que sus bragas requerían. A cada zapateta, repetía: - A la gala de San Martín” (CORDE, 1605, López de Úbeda, Francisco, La pícara Justina).

(b) “- Ven aquí a comer este cachín de pan y este güevo. Y Pedro le dijo:No, señor, que yo donde trabajo como. Y seguía sentao en el arca y no podían aquéllos sacar la comida pa comer. Y por la noche le dijo el amo a Pedro: - Güeno, ahora a comer su cachín de pan en la cocina, porque allí está su güevo" (CORDE, 1920, Anónimo, Cuentos populares españoles).

En los ejemplos, (a) y (b) se observa que la forma nominal asociada al determinante 'su' presenta sufijos diminutivos, -ín e -ito (y sus correspondientes variables flexivas), reforzando, por tanto, el valor apreciativo de la construcción correspondiente. Este uso, posteriormente, se evidencia además en distintas zonas de América hasta la actualidad, como lo muestra el caso (c):

(c) "Fue el padre Chuecas quien nos contó que para, catequizar a un curaca salvaje, lo llevaron a una capilla en momentos de celebrase misa, y concluida ésta le preguntaron que le había parecido la misa. Tiene de todo su poquito -contestó el curaca-. Su poquito de comer, su poquito de beber y su poquito de dormir" (CORDE, 1883, Palma, Ricardo, Tradiciones peruanas).

El Corpus de Referencia del Español Actual (CREA) de la RAE muestra que la construcción su poquito (con valor aproximativo y muchas veces afectivo, seguido del complemento del nombre correspondiente o de la forma nominal a la que determina) se encuentra por diversas zonas de América hispana durante el siglo XX: México, Perú, Venezuela, España, República Dominicana, Cuba, Puerto Rico, en ejemplos como: 'su poquito de sal', 'su poquito de orgullo', 'su poquito de pena', 'su poquito de whisky', 'su poquito de mala leche', 'estudiar su poquito', 'cogió su poquito de miedo', 'dramatizando su poquito', 'acompañarla su poquito'.

Con respecto al valor afectivo, vinculado a diminutivos, evidenciamos cómo, cuando se rastrea la frase [[tomarse / se tomó] + su vino], siempre el uso es el del posesivo regular (parafraseable por la construcción [se tomó el vino suyo], pero cuando se busca el grupo nominal con sufijo diminutivo, su vinito, el uso corresponde al aproximativo afectivo: "que fueran a jugar una partidita de dominó y su vinito y tal" (CREA, Venezuela, corpus oral).

Con respecto al uso aproximativo, testimoniado tanto en las principales obras sobre chilenismos como en otras de habla hispana e incluso románica (Corominas, 
1983), Román (1901-1918), citando a Santa Teresa, s. XVI, en la 6a acepción de la entrada 'su' señala:

"Hay un su impersonal y de un significado muy particular, que no hallamos en el Dicc. ni en las gramáticas: 'Habrá de aquí al mar sus veinte leguas: por eso le da su poco de miedo emprender este viaje’. Este su no se refiere a ninguna persona y su significado es unas, algunas, en la primera proposición: un, algún, en la segunda ¿Merece condenarse este uso? Así parece a primera vista, y más cuando está en abierta contradicción con las personas que obran en la oración, como en esta: 'Tenemos su poco de miedo de hacer este viaje', 'Ahora sus trabajos pasaremos, pero ello no volverá atrás"”.

Como se observa en la descripción anterior, Román indica que no existe una referencia personal asociada al 'su' en los casos reseñados, pues su valor se aleja del tradicional, erigiéndose un sentido distinto, ponderativo y/o aproximativo, similar al de los determinantes indefinidos o indeterminados. Esta característica es compartida por los usos actuales, que se detallaran más adelante.

Morales (1987), por su parte, le atribuye igualmente a la forma 'su' un valor aproximativo y/o ponderativo. El autor señala: 'empléase antepuesto con valor aproximativo: 'Llevábamos caminando su media cuadra cuando llegamos', 'Veinte funciones y reunimos sus seis mil volúmenes'. Para referir al valor ponderativo, entrega los siguientes ejemplos: 'Dice que chicharrea su poco', 'siempre le ponía sus pesitos por la viuda del patrón', ‘pegó su guapo rebuzno'. Al igual que en casos anteriores, se evidencia en los grupos nominales correspondientes elementos apreciativos, como adjetivos calificativos y sufijos diminutivos.

Cuervo (1955) no presenta el uso ni en sus Apuntaciones Críticas ni en el Diccionario (Cuervo, 1998), pero Restrepo (1943), algunos años después, complementando los estudios de Cuervo sobre el lenguaje bogotano, sí lo recoge en las Apuntaciones idiomáticas: Se usa para ponderar el sustantivo que modifica, y confieso que me agrada este modo de hablar aunque lo condenan algunos autores picajosos: 'Tiene sus años". Cabe señalar, no obstante, que no se explaya en los matices semánticos.

Otros antecedentes de los valores ponderativo y aproximativo son abordados por Moliner (2007). La autora señala el siguiente ejemplo, a propósito de la forma suyo, muy similar a los casos presentados por Morales (1987): ‘este mueble pesa lo suyo' (en Chile diríamos: 'tiene su peso'). Corominas (1983) añade un ejemplo de uso del valor aproximativo $\mathrm{y} / \mathrm{o}$ indeterminado en lengua catalana del que no encontramos equivalente en el 'Dicc. Etimológico Castellano' (puesto que siempre remite a los gramáticos cuando se trata de funciones). El ejemplo lo pone en Fraseología, comentando el uso de la forma arcaica sos: 'Ha costat sos duros per 'ha costat força diners $i$ no t'ho vull precisar' quan a algú li demanen que digui el que se n'han fet d'una compra valuosa'. En este caso 'ha costado sus duros' ('ha costat sos duros') tiene un valor aproximativo, 
cuando no se quiere precisar. Agrega Corominas (1983) que este uso lo ha escuchado él mismo de gente de origen popular de Barcelona, sobre todo de 'velles $i$ vells', viejas y viejos, y que corresponde a una frase hecha 'on s'ba conservat excepcionalment l'us del possessiu son, amb un paper en que, en les frases quotidianes, ja només s'admet seu'.

En síntesis, el origen de nuestro uso coloquial de 'su', aproximativo, ponderativo y afectivo, con función de determinante (reemplazable por los determinantes un, una), tiene sus orígenes en la lengua latina, probablemente con extensión románica, y lo encontramos testimoniado tempranamente en España y posteriormente en otros países hispanoamericanos, con pervivencia en todas estas zonas. Se lo describe en diccionarios de chilenismos como un uso particular coloquial con valor aproximativo, pero vemos que en fuentes tempranas españolas y americanas también está testimoniado, aunque probablemente tenga menor arraigo que en Chile.

\section{Metodología}

\subsection{Corpus}

El corpus que sirvió de base para el análisis está conformado por las 108 entrevistas sociolingüísticas que conforman el corpus de Santiago de Chile en el Proyecto para el Estudio Sociolingüístico del Español de España y América (PRESEEA) 7 . Las entrevistas fueron hechas aplicando los supuestos metodológicos sugeridos por Labov (1983), es decir, se realizaron entrevistas semiestructuras clásicas siguiendo el modelo del autor para la sociolingüística. El principal valor de esta propuesta, como sabemos, es que permite obtener diferentes tipos de registros, desde el más formal hasta el más vernacular.

\subsubsection{Población}

Para la conformación de la muestra de sujetos entrevistados se consideró la población santiaguina ${ }^{8}$. El cuestionario de la entrevista se aplicó a una muestra por cuotas con afijación uniforme (López, 1994). La muestra así conformada comprende un total de 108 individuos, distribuidos proporcionalmente como se indica en la Tabla 1.

Tabla 1. Distribución de sujetos de la muestra por nivel educacional, sexo y edad, según PRESEEA-SA.

\begin{tabular}{|c|c|c|c|c|c|c|c|}
\hline \multicolumn{8}{|c|}{ Grupo de edad } \\
\hline \multirow{2}{*}{ Nivel educacional } & \multicolumn{2}{|c|}{$20-34$} & \multicolumn{2}{|c|}{$35-54$} & \multicolumn{2}{|c|}{55 y más } & \multirow[t]{2}{*}{ Totales } \\
\hline & $\mathbf{H}$ & M & $\mathbf{H}$ & $\mathbf{M}$ & $\mathrm{H}$ & $\mathbf{M}$ & \\
\hline Alto & 6 & 6 & 6 & 6 & 6 & 6 & 36 \\
\hline Medio & 6 & 6 & 6 & 6 & 6 & 6 & 36 \\
\hline Bajo & 6 & 6 & 6 & 6 & 6 & 6 & 36 \\
\hline Totales & 18 & 18 & 18 & 18 & 18 & 18 & 108 \\
\hline
\end{tabular}




\subsubsection{Procedimiento de estratificación empleado}

Siguiendo el sistema de estratificación del Proyecto PRESEEA, la muestra se estratificó de acuerdo con sus respectivos niveles de instrucción, es decir, según la equivalencia entre los niveles de estudios básico, secundario y superior con los niveles sociales bajo, medio y alto, respectivamente. Además, con el propósito de garantizar la homogeneidad en la composición de los distintos estratos de la muestra y, por lo tanto, la representatividad de los mismos, se complementó dicho sistema de estratificación con el procedimiento de estratificación empleado por el proyecto de Estudio Sociolingüístico del Español de Chile, ESECH (San Martín \& Guerrero, 2015).

\subsection{Procedimiento analítico}

El análisis tuvo tres etapas fundamentales: 1) selección de todos los contextos en que el 'su' tenía función aproximativa, ponderativa y afectiva, 2) construcción de una clasificación y categorización semántico-discursiva de los contextos de aparición del fenómeno, 3) asociación entre el empleo de la partícula en estudio y los factores sociodemográficos de los hablantes -sexo, edad y nivel educacional-.

Para (2) se seleccionaron los casos más prototípicos y recurrentes de empleo de la partícula 'su' con valor afectivo y ponderativo en el corpus. Luego de ello, se sistematizaron los casos y se desarrolló una primera clasificación semántico-discursiva los elementos determinados por 'su'. Para (3), se incluyó tanto análisis descriptivo como inferencial. El grado de significación se definió en el 5\%, según el cual p<0,05 es estadísticamente significativo. Estos procedimientos siguen las sugerencias de Moreno (1990), López (1994) y Hernández y Almeida (2005).

\section{Resultados}

En lo sigue, se presentan los principales resultados de este esta investigación, siempre con la intención de cumplir los objetivos declarados inicialmente. Para ordenar dichos hallazgos, dividimos este apartado en dos grandes dimensiones: una cuyo foco es la caracterización gramatical de la partícula 'su' con valor afectivo y ponderativo, y otra dedicada al estudio de la distribución sociolingüística del fenómeno investigado.

\subsection{Comportamiento morfosintáctico del determinante 'su' con valor aproximativo, ponderativo y afectivo}

En lo que refiere a las estructuras identificadas y a las características morfosintácticas del elemento determinado por 'su', en el corpus analizado es posible evidenciar dos polos claramente definidos; por un lado, un polo $(+)$ léxico y $\left(^{+}\right)$ afectivo, en el que el elemento determinado por 'su' aparece modificado por adjetivos 
calificativos altamente valorativos o evaluativos (Varela, 2005), como lo muestran los siguientes ejemplos:

(8) no se pues la cena sus buenas papas con mayo (SCHI_H11_003).

(9) lo pasamos en la casa // en familia // eeh / su típico asado (SCHI_H12_041).

(10) un buen vinito de la zona puede ser / si es que estoy en el sur / y sus buenas papas cocidas (SCHI_H21_015).

(11) es tradición ya comer sus ricas empanadas pero este año no pude (SCHI_M12_047).

En términos de la posición del adjetivo, pareciera haber una tendencia a una posición prenominal. Según Torrego (1997) cuando el adjetivo va antepuesto, el adjetivo no especifica un subtipo, como sí lo haría en posición postnominal, sino que resalta una característica ya presente en la definición misma del sustantivo (de ahí su nombre de ‘explicativo' o ‘epíteto'). En la posición prenominal, el adjetivo indica una valoración o propiedad que por ser inherente al referente del sustantivo, carece de la capacidad de especificar un subconjunto. Algo muy interesante en términos comunicativos ocurre cuando tenemos una frase nominal con un adjetivo que no reitera parte del sustantivo, pero que se pone en posición de epíteto. Llevada esta explicación al uso afectivo, pareciera ser que el adjetivo buena, por ejemplo, forma parte, para los hablantes, del sustantivo en cuestión. Según lo anterior, estas entidades en sí mismas poseerían $(+)$ afectividad y $(+)$ cercanía para el hablante, de ahí que, además del determinante afectivo correspondiente, se utilice un adjetivo calificativo en la posición ya mencionada. Por otro lado, hacia un polo (-) léxico, existen casos en los que el elemento determinado presenta morfemas derivativos apreciativos, tales como sufijos diminutivos y aumentativos, como lo muestran los siguientes ejemplos:

(12) ¿qué se toma ahí? vino // vino / vino // no vino chela // su ponchecillo // vino durazno no sé (SCHI_H13_074).

(13) por ejemplo una buena entrada // un plato un plato de fondo exquisitos normalmente carne / pero una carne bien preparada ¿ya? bien preparada su traguito eso (SCHI_H33_097).

(14) Luis Miguel o cosas así Luis Miguel o no sé todo lo comercial así hasta regue hasta se pega sus reguetonas así (SCHI_M11_007).

Según la RAE (2010), se llaman apreciativos los sufijos que se añaden para expresar la valoración afectiva que se hace de las personas o las cosas, transmitiendo connotaciones subjetivas. En estos casos decimos que se acerca a un polo (-) léxico por tratarse de elementos morfemáticos (entendiendo el morfema como un recurso 
más gramatical que léxico), aunque reconocemos que la sufijación apreciativa (que incluye a los sufijos diminutivos, aumentativos y peyorativos) posee características que la sitúan en un estadio intermedio:

“algunas de sus características son propias de la flexión: es regular, no forma nuevas palabras ni altera su categoría. Sin embargo, la modificación que introduce no interesa a ninguna regla sintáctica ni expresa ninguna propiedad flexional" (Di Tullio, 2007: 28).

Además de lo anterior, por tratarse de valoraciones del hablante, no aporta un nuevo significado léxico como tal, sino más bien permite observar cómo y desde dónde el hablante se sitúa para evaluar un fenómeno o entidad particular. Según esto, el 'su' se erigiría - eventualmente y según el sufijo con el que se combine- como un recurso de atenuación o valoración positiva o altamente afectiva de una realidad cercana al hablante. Según lo anterior expuesto, sería posible proponer un continuum de significado apreciativo a partir de los recursos empleados, que va desde la menor a la mayor afectividad: 'su' afectivo $\rightarrow$ sufijación apreciativa $\rightarrow$ adjetivos calificativos (sus asados $\rightarrow$ sus asaditos $\rightarrow$ sus ricos traguitos).

Otro aspecto interesante a considerar es el que se relaciona con un análisis más sintáctico de las estructuras correspondientes. En algunos casos no es posible evidenciar una forma verbal asociada a la estructura nominal correspondiente, como lo muestran los siguientes ejemplos:

(15) no se pues la cena a) sus buenas papas con mayo y su ensaladita ya a la chilena en ese tiempo que ya ya viene / es como el verano ya / echo b) su choclo con mayo su buen costillar o su pollito (SCHI_H11_003).

(16) generalmente salíamos con alguna minita / su copetito / y gracias a Dios él está bien (SCHI_H12_037).

Mientras que en el primer caso del ejemplo (15a) y en el ejemplo (16) pareciera ser que se estuviera construyendo un escenario de la festividad (pues se presentan ciertos elementos) y, por tanto, se enumera ciertas entidades, en el segundo caso del ejemplo (15b) el elemento enfatizado está asociado a un proceso particular, 'echar'. A la luz de estos casos, es posible postular una función 'presentacional' y contextual de las estructuras nominales con 'su' afectivo, en tanto introduce al discurso la entidad u objeto correspondiente, como, por ejemplo, las bebidas alcohólicas copetito y chelita en los siguientes contextos:

(17) generalmente salíamos con alguna minita / su copetito / y gracias a Dios él está bien (SCHI_H12_037).

(18) según pues / no pues / siempre su chelita pero según el motivo (SCHI_H12_039). 
Esta característica sería la que lo habilitaría para aparecer en sintagmas con el verbo haber. Esta función se justifica en que actualmente este uso aparece en contextos orales cargados de elementos deícticos e interpretativos. Por tratarse de un uso característico de la oralidad del español de Chile, el tono lúdico o picarón de la forma con 'su' es compartido por la comunidad correspondiente en la mayoría de los casos.

Si pensamos en un caso presentacional, como el que sigue, que se introduzca al discurso un cigarrillo de marihuana, pito, en un contexto de celebración (x) es algo común para el hablante, algo propio de x. Lo mismo sucede con los tragos del ejemplo (20):

(19) comemos lo típico chileno / o un marisquito después / igual su pitito también (SCHI_H12_037).

(20) que whisky / que su tequila / que su combinado entonces (SCHI_H11_004).

Como síntesis de las posibles estructuras en las que el 'su' afectivo aparece en el corpus, se presenta a continuación un detalle de los tipos de grupos nominales trabajados:

a) ['su' + sustantivo] después al otro día hacíamos su asado (SCHI_H33_097).

b) ['su' + sustantivo con apreciativo] les pega su llamadita y ya pues juntémonos en tal día (SCHI_H11_002).

c) ['su' + sustantivo (con sufijo apreciativo) + adjetivo] bueno ahora no estoy tomando tanto pero/ su roncito loco (SCHI_H13_075).

d) ['su'+ adjetivo + sustantivo (con sufijo apreciativo)] eeh a ver / su buen vino / harto vinito vinito / del bueno por supuesto / eeh sus buenas empanadas / de horno / calientita pero con harta carne (SCHI_H22_052).

e) ['su'+ sustantivo + complemento del nombre] en una cena así / y su buen trozo de pan de pascua (SCHI_H22_052).

\subsubsection{Construcción de una clasificación y categorización semántico- discursiva de 'su'}

Los elementos determinados por 'su' en el corpus analizado son altamente inanimados; se trata de objetos, alimentos o actividades. Dado que el propósito de esta parte de la investigación es proponer una clasificación y categorización semánticodiscursiva de los usos de la partícula 'su' en los materiales revisados, se ha optado por presentar una descripción cuyo enfoque no sea la cuantificación. Por consiguiente, se pueden revisar, aunque de forma preliminar, las categorías de uso y esbozar 
proyecciones de investigación en relación con la frecuencia de empleo de 'su' y de su distribución tipológica en términos estadísticos.

Los casos analizados podrían esquematizarse y agruparse de la siguiente manera.

Tabla 2. Clasificación semántico-discursiva los elementos determinados por 'su'.

\begin{tabular}{|c|c|c|c|c|c|}
\hline $\begin{array}{c}\text { Aspectos a } \\
\text { evaluar }\end{array}$ & $\begin{array}{c}\text { Bebidas y } \\
\text { licores } 9\end{array}$ & Alimentos & $\begin{array}{c}\text { Utensilios } \\
\text { domésticos o } \\
\text { posesiones } \\
\text { materiales }\end{array}$ & $\begin{array}{c}\text { Actividades } \\
\text { procesos y } \\
\text { eventos }\end{array}$ & $\begin{array}{c}\text { Seres } \\
\text { humanos }\end{array}$ \\
\hline $\begin{array}{l}\text { Escala de } \\
\text { Animacidad }\end{array}$ & $(-)$ animado & (-) animado & (-) animado & (-) animado & $(+)$ animado \\
\hline Ejemplos & $\begin{array}{l}\text { su } \\
\text { ponchecillo } \\
\text { su traguito } \\
\text { su copetito } \\
\text { su bebida } \\
\text { su jotecito } \\
\text { su cervecita } \\
\text { su vinito } \\
\text { su chelita } \\
\text { su copetito }\end{array}$ & $\begin{array}{l}\text { sus buenas papas } \\
\text { con mayo } \\
\text { su ensaladita a la } \\
\text { chilena } \\
\text { su choclo con } \\
\text { mayo } \\
\text { su pollito asado } \\
\text { su comidita } \\
\text { su papitas con } \\
\text { mayo } \\
\text { su arrocito }\end{array}$ & $\begin{array}{l}\text { su jarrito } \\
\text { su auto } \\
\text { sus buenas } \\
\text { camas } \\
\text { su buena ropa } \\
\text { su auto } \\
\text { su buen zapato } \\
\text { su buen } \\
\text { pantalón }\end{array}$ & $\begin{array}{l}\text { sus } \\
\text { charchazos } \\
\text { sus palabrazos } \\
\text { sus salidas } \\
\text { bacanes al } \\
\text { circo } \\
\text { sus ataques de } \\
\text { locura } \\
\text { su farra }\end{array}$ & $\begin{array}{l}\text { su minito rico } \\
\text { sus vedettos } \\
\text { en } \\
\text { pelota }\end{array}$ \\
\hline
\end{tabular}

Como lo muestra la Tabla 2, únicamente en el grupo 'seres humanos' encontramos elementos nominales animados. No obstante lo anterior, y considerando el contexto de aparición, en estos casos más que referir a las entidades como sujetos animados, se hace referencia más bien a su cargo o se les atribuye rasgos o una naturaleza objetual o inanimada (como si se tratasen de cosas o alimentos). En este sentido, podría postularse que estas excepciones responden más bien a un proceso de 'metaforización' en el que las entidades correspondientes se asumen como cosas o alimentos. En estos casos, se evidencia una posible doble lectura debido al fenómeno que Palma (2003) explica refiriéndose al lenguaje como una actividad simbólica en la cual se llevan a cabo actos de sustitución, que no se limitan a un acto semántico, sino también incluye la capacidad cognitiva humana de superar la propia perspectiva estableciendo relaciones mentales. De esta manera, se extrapola lo netamente lingüístico para viajar al plano y dimensión de la mente:

"la metáfora es una figura por la cual se transporta, por decirlo de alguna manera, la significación de una palabra a otra significación que no le conviene, sino en virtud de una comparación que está en el espíritu" (Palma, 2003: 261).

Ahora bien, en lo que refiere a las otras categorías, podemos apreciar que estas refieren a realidades cercanas a los hablantes correspondientes. Las dos primeras, que refieren a una dimensión culinaria, aparecen en contextos de narraciones sobre festividades familiares como navidad, año nuevo, cumpleaños o fiestas y celebraciones juveniles en las que sucedieron ciertos hechos gratificantes para el hablante. En estos 
contextos, los informantes describen los alimentos y bebidas típicas que son ingeridas en la celebración, como lo muestran los siguientes ejemplos:

(21) a ver / su buen vino / harto vinito vinito / del bueno por supuesto / eeh sus buenas empanadas / de horno / calientita (SCHI_H22_052).

(22) lo que no puede faltar son las papitas duquesas / que es lo infaltable / en una cena así / y su buen trozo de pan de pascua (SCHI_H22_052).

Sobre la tercera y la cuarta, en ambos casos, utensilios y actividades, las realidades descritas son cotidianas y cercanas al hablante. Lo anterior justificaría la valoración que este realiza y, además, el alto grado de afectividad asociado a estas entidades (sobre todo porque se asocian, en general, a situaciones o recuerdos emotivos en sus vidas), como lo muestran los siguientes ejemplos:

(23) nos juntamos a bailar sus cuecas salimos para las fonda con mi hijo bailamos (...) con el papá también baila trataba de bailar ahí su cueca y eso hacemos (SCHI_M11_007).

(24) la mayoría de amigos que tengo ninguno es flaite/ se le caen su chuchada como a todos normal (SCHI_M11_011).

Cabe señalar que, a propósito del ejemplo (24), no es el contexto mismo el que tiene una apreciación y afectividad positiva (pues en este caso el informante alude a su desprecio por el grupo denominado 'flaite'), sino más bien el elemento determinado por el 'su'. En este caso la "chuchada" está bien vista y es positivamente valorada por el informante, lo que se ve reforzado por su comentario posterior 'como a todos normal'.

\subsection{Distribución sociolingüística de la partícula 'su'}

En esta sección del trabajo, se presenta, por una parte, la distribución de empleo de 'su' y, por otra, se lo asocia con las variable sexo, edad y nivel educacional de los informantes.

Tabla 3. Distribución de empleo de ‘su’ afectivo en el corpus PRESEEA-SA.

\begin{tabular}{|l|c|c|c|c|c|c|c|}
\hline \multicolumn{7}{|c|}{ Grupo de edad } \\
\hline \multirow{2}{*}{ Nivel educacional } & $\mathbf{2 0 - 3 4}$ & \multicolumn{3}{|c|}{$\mathbf{3 5}$} & $\mathbf{5 5}$ y más & Totales \\
\cline { 2 - 9 } & $\mathbf{H}$ & $\mathbf{M}$ & $\mathbf{H}$ & $\mathbf{M}$ & $\mathbf{H}$ & $\mathbf{M}$ & \\
\hline Alto & 3 & 1 & 0 & 1 & 4 & 0 & 9 \\
\hline Medio & 27 & 6 & 6 & 1 & 1 & 1 & 42 \\
\hline Bajo & 12 & 12 & 4 & 5 & 2 & 4 & 39 \\
\hline Totales & 42 & 19 & 10 & 7 & 7 & 5 & 90 \\
\hline
\end{tabular}

Como se desprende de la tabla precedente, desde el punto de vista meramente descriptivo, son los hablantes con estudios medios y bajos los que más utilizan el 'su' 
con los valores que aquí hemos descrito, $42 / 90$ (46,7\%) y 39/90 (43,3\%), de manera respectiva. Los hablantes con mayor cantidad de estudios prácticamente no utilizan esta forma de 'su' (9/90, 10\%). Dicho hallazgo resulta muy interesante toda vez que consideramos que las investigaciones en sociolingüística del español han demostrado que los hablantes de los grupos superiores de la escala social-que suelen coincidir con los que tienen mayor escolaridad- utilizan un discurso más directo y competitivo, y que se trata, además, de hablantes hombres (Blas, 2005), lo que podría repercutir en que estos sujetos no empleen las formas aproximativas y afectivas descritas. En nuestro estudio, de los 9 casos registrados en el grupo con nivel de estudios alto, 7 corresponden a entrevistas de hombres y apenas 2 a discursos de mujeres. Este patrón se repite en el grupo con estudios medios, donde de un total de 42 casos, 34 corresponden a usos masculinos y solo 8 a usos femeninos. El único grupo que presenta un comportamiento divergente, aunque con una diferencia de frecuencias muy menor, es el grupo con estudios bajos, donde de los 39 casos registrados, 18 son utilizados por hombres y 21 por hablantes mujeres. Pese a esta divergencia, en términos generales, del total de usos 59/90 (65,5\%) son registrados en discursos masculinos mientras que solo $31 / 90(34,4 \%)$ son utilizados por mujeres, es decir, los hombres casi duplican a las mujeres en su empleo de 'su' con valor afectivo y ponderativo.

Los resultados descritos previamente muestran que el fenómeno en estudio no se comporta como otros que se han relacionado con la mayor afectividad del discurso femenino, pues se trata de un recurso más recurrente en los hombres. Eckert y McConnell (1992, citados en Wodak \& Benke, 1998) postulan que las investigaciones sobre las diferencias de género se han centrado en el conservadurismo, el prestigio consciente, la movilidad, la inseguridad, la diferencia, la expresividad emocional, la sensibilidad hacia otros y la solidaridad, en lo que respecta a las mujeres. Por lo mismo, no hubiese sido extraño que se tratara de un tipo de uso muy femenino. Sin embargo, otras hipótesis señalan que son los hombres quienes emplean un discurso más vernáculo. Así, las formas lingüísticas más tradicionales se consideran como 'prestigiosas'. Precisamente este aspecto fue el que nos llevó a proponer la hipótesis de que se trataría de un fenómeno más frecuente en hombres.

De acuerdo con Silva-Corvalán (2001), el uso de determinadas variables lingüísticas se considera prestigioso, es decir, adquiere un valor positivo puesto que facilita el ascenso en la escala social y, además, se trata de formas lingüísticas aceptadas por las gramáticas normativas, por lo que generalmente son asociadas a la clase media alta culta. A este respecto, Coates (2009) señala que las investigaciones sociolingüísticas clásicas - la de Labov en Nueva York y la de Trudgill en Norwich — que estudiaron variaciones lingüísticas en relación con variables extralingüísticas, revelaron una clara estratificación social y dieron lugar a dos conceptos: el de 'prestigio' y el de 'estigma'. El primero se relaciona con las formas lingüísticas que suelen emplear los grupos 
sociales de más alto estatus, por lo que en el proceso de estandarización se llega a la noción de 'correcto'. El 'estigma', por el contrario, se relaciona con las formas no estándares. Conforme creció el interés en el uso y permanencia de formas no estándares, estas variantes no estándares fueron denominadas 'vernaculares'.

En lo que respecta al uso de 'su' que acá nos ocupa en relación con la edad de los hablantes, se trata, como vemos de un uso mayoritariamente de los jóvenes, esto es, $61 / 90(67,7 \%)$. En el grupo de edad intermedia se registran 17/90 (18,8\%) casos y en el grupo de 55 años y más apenas 12/90 (13,5\%) ocurrencias. Es decir, la descripción de los datos nos permite señalar que conforme avanza la edad de los sujetos disminuye la utilización de 'su' con valor afectivo y aproximativo. Pese a que no comprobamos que se tratara de hallazgos estadísticamente significativos, es interesante que la forma no marcada, en este caso, la posesiva, se repita para el estudio del presente histórico (Guerrero, 2014) y del 'pero' enfático (Arriagada \& Guerrero, 2016) en la misma comunidad de habla, esto es, hay una disminución en la frecuencia de uso de estas partículas con otros valores no convencionales que disminuye a medida que avanza la edad de los hablantes.

De acuerdo con los datos proporcionados previamente, el análisis descriptivo del fenómeno nos permite señalar que se trata de un uso de hombres jóvenes de la comunidad de habla santiaguina.

En lo que respecta al análisis inferencial de los datos, las pruebas de medias muestran que solo el nivel de estudios es estadísticamente significativo $(\mathrm{p}=0,04)$, como ilustra el siguiente gráfico. 


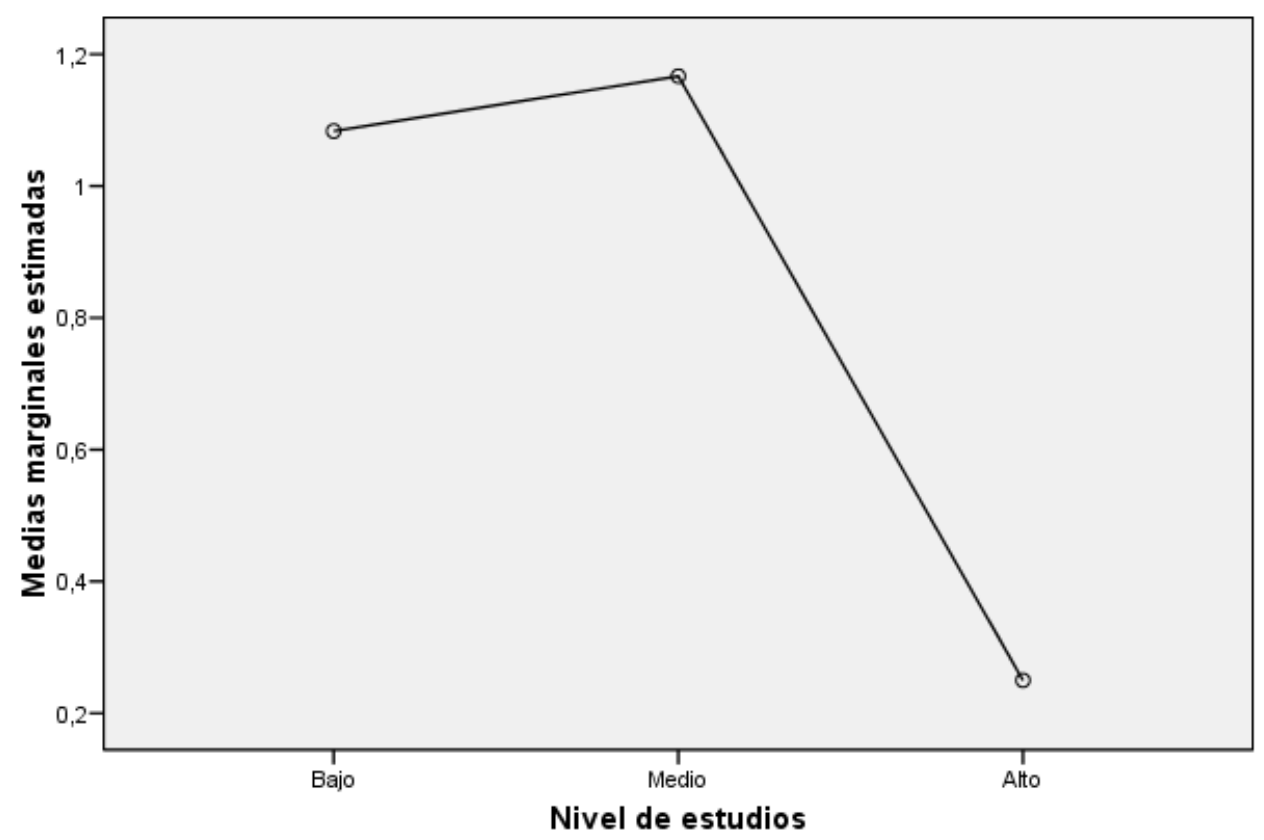

Gráfico 1. Medias marginales del empleo de ‘su’ afectivo según el nivel de estudios de los informantes.

Los datos reflejados en el gráfico muestran el promedio del uso de 'su' con valor afectivo, aproximativo y ponderativo en la muestra utilizada según el nivel de estudios de los informantes. Las medias son de 0,3 en el nivel alto, 1,1 en el bajo y 1,2 en el nivel medio. El análisis de variables en interacción señala que las medias para los hombres jóvenes del nivel de estudios bajo es de 2,0 y para los hombres jóvenes del nivel de estudios medio es de 4,5. Este último grupo se constituye, por lo tanto, como el que más emplea la partícula 'su' con el valor que le hemos asignado en esta investigación. El resto de los valores inferenciales obtenidos no difieren de los descriptivos.

Para complementar los datos previos y sobre todo porque se trató de un fenómeno cuya frecuencia fue escasa, hemos realizado una prueba no paramétrica de ji cuadrado por presencia y ausencia del fenómeno, de manera independiente de su cantidad de ocurrencias. Los datos reflejan que el valor p para el nivel de estudios es de 0,04 y los valores de la tabla de contingencia respectiva quedan ilustrados en el Gráfico 2. 


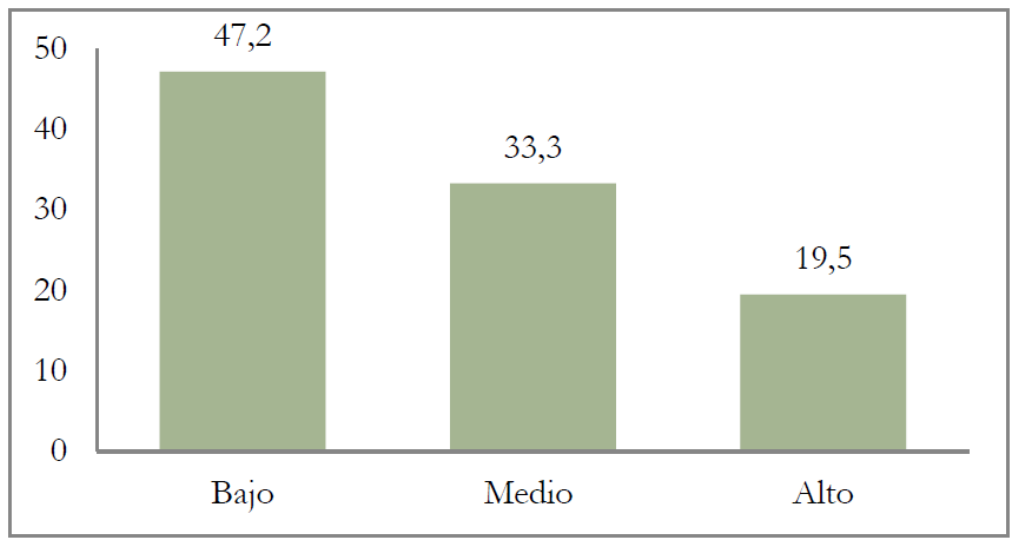

Gráfico 2. Porcentaje del empleo de ‘su' afectivo asociado con el nivel de estudios de los informantes.

Del total de informantes, solo 17 utilizan la partícula con valor afectivo, no obstante, se trata de un gráfico relevante, ya que muestra que cuando el fenómeno se utiliza se hace en una escala inversamente proporcional, es decir, disminuye su inclusión a medida que avanzamos en el nivel de estudios. Esto permite verificar que podría tratarse de una forma estigmatizada socialmente, relacionada con las formas no estándares.

\section{CONCLUSIONES}

Las conclusiones más relevantes de esta investigación son las siguientes:

En relación con el análisis léxico-gramatical, se pudo concluir que el 'su' como determinante afectivo constituye un uso y valor del posesivo diferenciado, no descrito en las gramáticas ni en estudios posteriores. Este uso no solo posee valores semánticos y evaluativos distintos al valor posesivo tradicional, sino que además evidencia diferencias morfosintácticas posicionales, morfemáticas y funcionales.

El análisis permitió verificar que los sintagmas nominales estudiados se caracterizan por presentar, preponderantemente, morfemas derivativos apreciativos, sean estos diminutivos o aumentativos. Sobre los diminutivos, se evidencia las formas -illo, -ito, con sus correspondientes variantes flexivas, y sobre los aumentativos, preponderan los sufijos -azo y -ona.

En lo que respecta a la clasificación semántico-discursiva del fenómeno en estudio, los hallazgos descriptivos apuntan a que es posible agrupar los casos en los que se usa 'su' en cinco ejes temáticos generales: 1) bebidas y licores, 2) alimentos, 3) utensilios domésticos o posesiones importantes, 4) actividades, procesos y eventos y 5) seres humanos. Mientras que los grupos 1 al 4 presentan un bajo nivel de animacidad, el grupo 5 es altamente animado. No obstante, este último presenta ciertos rasgos que 
permiten proponer un proceso de metaforización en el que estas realidades son concebidas como objetos o alimentos.

Por su parte, el análisis sociolingüístico del empleo de 'su' con valor aproximativo, afectivo y ponderativo en el español de Chile permitió comprobar la hipótesis inicial, que señalaba que las características sociodemográficas de los hablantes de español en Santiago de Chile están asociadas con el empleo del fenómeno en estudio y, además, que se halla más en los hablantes hombres de la comunidad de habla en estudio, sobre todo, en los jóvenes con menos nivel de estudios.

Si bien las conclusiones anteriores son relevantes para los propósitos de esta investigación, debemos precisar que el corpus analizado representa únicamente la variedad de habla santiaguina, por lo que resulta necesario llevar a cabo investigaciones mayores, para determinar si el uso del 'su' que aquí nos atañe se comporta de la misma forma en todo el territorio chileno. Por lo mismo, las categorías semántico-discursivas que proponemos son generales. Consecuentemente, entre las proyecciones del trabajo está, en primer lugar, la necesidad de acotar dichas categorías, de manera que puedan realizarse estudios de corte cuantitativo y presentar la distribución tipológica de 'su' en términos estadísticos. En segundo término, también puede resultar relevante incluir un análisis del carácter aspectual de las construcciones sintácticas presentadas, con el propósito de contribuir a la descripción más detallada del fenómeno investigado.

\section{REFERENCIAS BIBLIOGRÁFICAS}

Alarcos, E. (1999). Gramática de la lengua española. Madrid: Espasa Calpe.

Arriagada, S. \& Guerrero, S. (2016). El uso de ‘pero’ enfático en el corpus PRESEEA de Santiago de Chile. Estudios Filológicos, 57, 43-63.

Blas, J. L. (2005). Sociolingüística del español. Desarrollos y perspectivas en el estudio de la lengua española en contexto social. Madrid: Cátedra.

Benveniste, E. (1970). El aparato formal de la enunciación. Langages. París: DidierLarousse, 5(17), 12-18.

Bosque, I. \& Demonte, V. (Dirs.) (1999). Gramática descriptiva de la lengua española. Madrid: Espasa.

Coates, J. (2009). Mujeres, hombres y lenguaje. Un acercamiento sociolingüistico a las diferencias de género. México: Fondo de Cultura Económica.

Company, C. (1991). La extensión del artículo en el español medieval. Romance Philology, 44(4), 402-424. 
Corominas, J. (1983). Diccionari etimoligic $i$ complementari de la llengua catalana. La Caixa, Barcelona: Curial Edicions Catalanes.

Costa, A. (1981). El posesivo en español. Sevilla: Universidad de Sevilla.

Cuervo, R. J. (1955). Apuntaciones críticas del lenguaje bogotano. Bogotá: Instituto Caro y Cuervo.

Cuervo, R. J. (1998). Diccionario de construcción y régimen de la lengua castellana. España: Herder.

De Bruyne, J. (1999). Las preposiciones. En I. Bosque \& V. Demonte (Dirs.), Gramática descriptiva de la lengua Española I (pp. 657-703). Madrid: Espasa.

Di Tullio, A. (2007). Manual de gramática del español. Buenos Aires: La isla de la luna.

Eguren, L. (2013). Cliticos léxicos y elipsis nominal [en línea]. Disponible en: http://www.ehu.es/ojs/index.php/asju

García, C. (1990). Historia de un uso popular: El posesivo ante nombre propio de persona. Revista de Filología Románica, 7, 219-230.

Guerrero, S. (2014). Una aproximación sociolingüística al empleo del presente histórico en narraciones de experiencia personal en hablantes de Santiago de Chile. Revista de Lingüistica Teórica y Aplicada, 52(2), 89-112.

Hernández, J. M. \& Almeida, M. (2005). Metodología de la investigación sociolingüistica. Málaga: Editorial Comares.

Huerta, N. (2003). Gramaticalización del posesivo. Un proceso hacia la abstracción. Medievalia, 35, 183-197.

Jiménez , T. (2006). El paradigma determinante en español: Origen nominativo, formación y características. Santiago de Compostela: Universidad de Santiago de Compostela, Servicio de Publicaciones e Intercambio Científico.

Labov, W. (1983). Modelos sociolingüísticos. Madrid: Cátedra.

López, H. (1994). Métodos de investigación lingüistica. Salamanca: Ediciones Colegio de España.

Moliner, M. (2007). Diccionario del uso del español. Madrid: Gredos.

Morales, F. (1987). Diccionario ejemplificado de chilenismos. Universidad de Playa Ancha: UPLACED.

Moreno, F. (1990). Metodología sociolingüistica. Madrid: Gredos. 
Morera, M. (1987). La unidad semántica del pronombre posesivo 'su'. Revista de Filología de la Universidad de La Laguna, 6, 259-282.

Palma, A. (2003). Sentido figurado y cognición: espacio virtual como espacio contenedor. Onomázein, 8, 231-274.

PRESEEA. (2014). Corpus del Proyecto para el estudio sociolingüistico del español de España y de América. Alcalá de Henares: Universidad de Alcalá [en línea]. Disponible en: [http://preseea.linguas.net].

Prieto, L. (1995-1996). Análisis sociolingüístico del dequeísmo en el habla de Santiago de Chile. Boletin de Filología, XXXV, 379-452.

Real Academia Española. (2005). Diccionario Panbispánico de Dudas. Bogotá: Real Academia Española.

Real Academia Española. (2010). Nueva gramática de la lengua española. Manual. Madrid: Espasa Libros.

Restrepo, R. (1943). Apuntaciones idiomáticas y correcciones de lenguaje. Bogotá: Cromos.

Román, M. A. (1901-1918). Diccionario de chilenismos y de otras voces y locuciones viciosas. Santiago de Chile: Imprenta San José.

San Martín, A. \& Guerrero, S. (2015). Estudio sociolingüístico del español de Chile (ESECH): Recogida y estratificación del corpus de Santiago. Boletín de Filología, 50(1), 221-247.

Silva-Corvalán, C. (2001). Sociolingüistica y pragmática del español. Washington: University Press.

Tesnière, L. (1994). Elementos de sintaxis estructural. Madrid: Gredos.

Torrego, L. (1997). Gramática didáctica del español. Madrid: SM.

Varela, S. (2005). Morfología léxica: La formación de palabras. Madrid: Taurus.

Wodak, R. \& Benke, G. (1998). Gender as a sociolinguistic variable: New perspectives on variation studies. En F. Coulmas (Ed.), The Handbook of Sociolinguistics (pp. 671-698). Oxford: Blackwell Publishing.

\section{NOTAS}

1 Este trabajo contó con el apoyo del concurso "Estadías Cortas de Investigación Internacionales" del Proyecto de Internacionalización UCH-1566 de la Vicerrectoría de Investigación y Desarrollo de la Universidad de Chile. 
2 Los estudios de posgrado de la autora fueron financiados por CONICYTPFCHA/MagísterNacional/2017 - 2217115.

${ }^{3}$ Los ejemplos extraídos del corpus están codificados de la siguiente manera: $\mathrm{SCHI}=$ Santiago de Chile; $\mathrm{H}=$ Hombre y $\mathrm{M}=$ Mujer. El primer número, luego del sexo del informante, corresponde al grupo etario: $1=20-34$ años; $2=35-54$ años y $3=55$ años y más. El segundo número corresponde al nivel educacional del informante: $1=$ estudios básicos completos o incompletos; $2=$ estudios medios completos o incompletos y $3=$ estudios universitarios completos o incompletos. El número que sigue al guion corresponde al número correlativo que reciben los sujetos que conforman la muestra. Los ejemplos están transcritos en ortografía convencional.

${ }^{4}$ Gracia tiene sus cuarenta años (Morera, 1987: 264).

5 "No se pues la cena tiene sus buenas papas con mayo y su ensaladita ya a la chilena en ese tiempo que ya ya viene / es como el verano ya / echo su choclo con mayo su buen costillar o su pollito asado / cachái esa es como como la cena su bebida y un vino si es que toman" (SCHI_H11_003).

${ }^{6}$ Véase, en complemento al punto, el estudio de los cambios semánticos del posesivo en su proceso de gramaticalización en Huerta (2003).

7 El PRESEEA es un proyecto para la creación de un corpus de lengua española hablada representativo del mundo hispánico en su variedad geográfica y social. Esos materiales se reúnen atendiendo a la diversidad sociolingüística de las comunidades de habla hispanohablantes. En la actualidad, el proyecto agrupa a cerca de 40 equipos de investigación sociolingüística, entre ellos, el de Santiago de Chile.

8 Por lo que refiere a los criterios de asignación de hablante nativo de Santiago de Chile, de acuerdo con Prieto (1995-1996: 399), se aplicaron las siguientes restricciones en la selección de los sujetos: 1) haber nacido y residido en forma ininterrumpida en Santiago; 2) haber residido en forma ininterrumpida en Santiago desde los cinco años de edad y 3) haber nacido en Santiago y haber residido en Santiago la mayor parte de sus vidas, salvo por periodos que sumados no superen los cuatro años en el tramo de 55 años y más y los tres años en el tramo de 35 a 54 años.

${ }^{9}$ El nivel de especificidad varía en esta categoría. Se evidencia preponderantemente el uso de las formas genéricas trago, cerveza (o chela en la variedad chilena) y vino, pero también es posible evidenciar tragos específicos como jote (se llama así en Chile al trago que mezcla vino tinto y bebida), Bailey (nombre de una marca específica de bebida alcohólica) o ron. 